\title{
FEDERICO CORRIENTE, TRAYECTORIA ACADÉMICA DE UN ARABISTA SINGULAR
}

\author{
FEDERICO CORRIENTE, ACADEMIC CAREER OF A UNIQUE ARABIST
}

\author{
M. a José CERVERA Fras \\ Universidad de Zaragoza \\ ÁNGELES VicENTE \\ Universidad de Zaragoza
}

\begin{abstract}
Resumen: Se recoge en este trabajo una semblanza de las actividades realizadas por el profesor Federico Corriente a lo largo de su fructífera vida académica y lo que han supuesto para la disciplina del arabismo. Se repasan aquí sus muy diversas e importantes aportaciones a la dialectología, la literatura o la historia.
\end{abstract}

Palabras clave: lengua árabe, dialectología, poesía estrófica, Alandalús.

\begin{abstract}
This paper is a biographical note including activities undertaken by Professor Federico Corriente along his fruitful academic career, and what they have meant to the discipline of Arabism. His very diverse and important contributions to dialectology, literature and history are reviewed.
\end{abstract}

Keywords: Arabic language, dialectology, stanzaic poetry, Alandalus. 


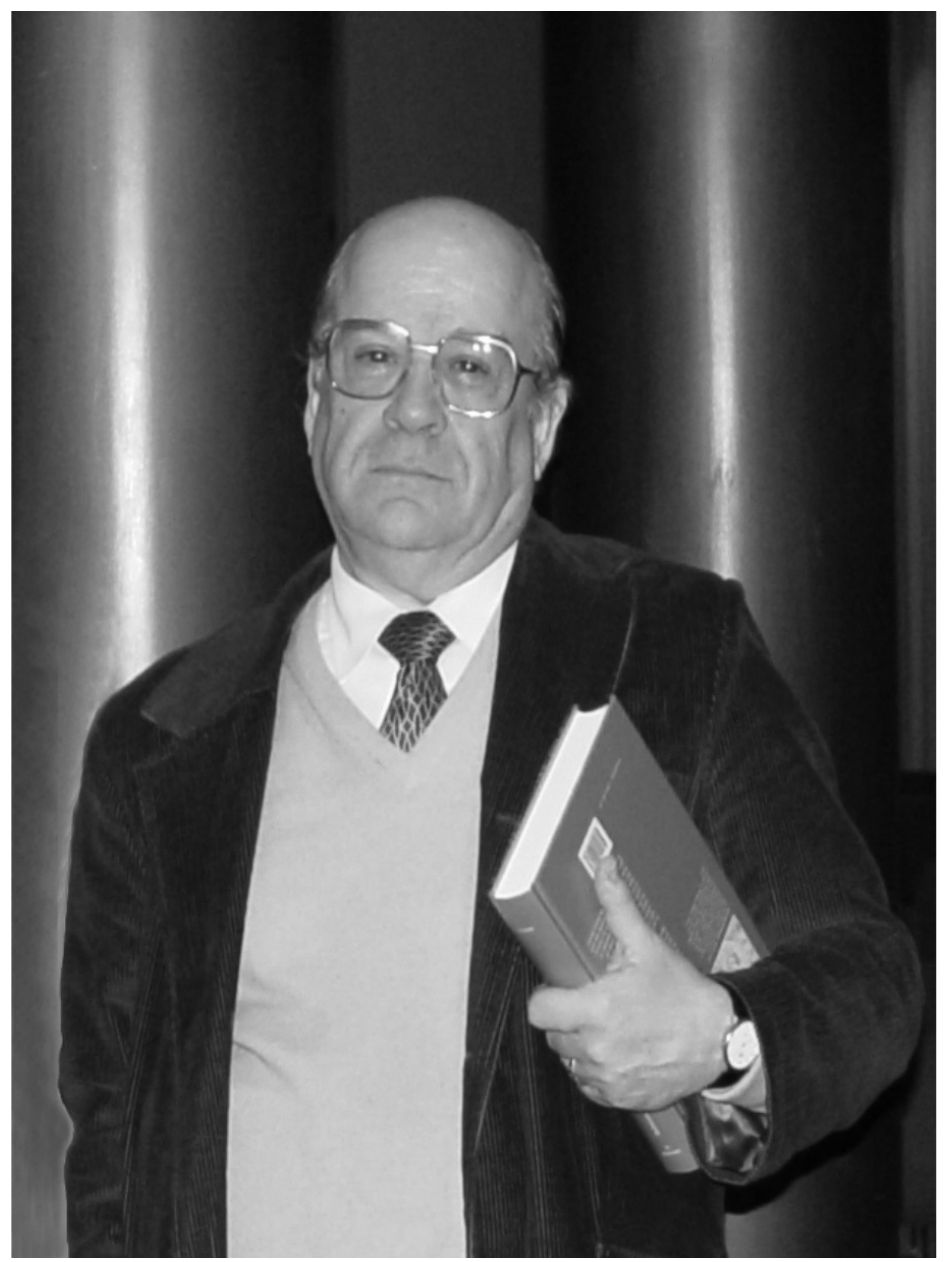

Federico Corriente Córdoba La Aljaferia, Zaragoza, 2005

Fotografía: Fernando Andú 
Las labores de docencia e investigación del profesor Federico Corriente son ciertamente singulares por su diversidad y abundancia. Varias han sido las universidades españolas y extranjeras en las que ha impartido sus lecciones, y así podemos afirmar que ha practicado su magisterio en tres continentes, desde la Universidad de El Cairo (1962-1965) y la Universidad Muhammad V de Rabat (1965-1968), pasando por la Universidad de Dropsie en los Estados Unidos (1968-1972), hasta desembarcar en España, donde ha sido catedrático en la Universidad Complutense de Madrid (1972-1976 y 1986-1991) y en la Universidad de Zaragoza (1976-1986 y 1991-2015), y algo que sorprenderá a muchos, por desconocido, investigador científico del Consejo Superior de Investigaciones Científicas, en excedencia desde 1972.

De todas estas instituciones, la Universidad de Zaragoza es en la que más años ha pasado, un total de treinta y cuatro en dos periodos diferentes, y en la que ha llegado a su jubilación como catedrático emérito; razón por la cual el Departamento de Historia Medieval, Ciencias y Técnicas Historiográficas y Estudios Árabes e Islámicos y su revista Aragón en la Edad Media han decidido dedicarle este artículo en homenaje, donde sus compañeras de despacho, discípulas y colegas, realizamos una breve semblanza de su trayectoria, pues es difícil recoger en unas pocas páginas una vida académica tan rica y fructífera.

Su actividad docente no solo es diversa por el número de instituciones a las que ha estado adscrito, sino por su capacidad para enseñar en varias lenguas diferentes y distintas materias como lengua española, lingüística semítica, lengua hebrea, lengua etiópica, literatura árabe y, sobre todo, lengua árabe. En el terreno de esta última, tuvo el acierto de dotar a los estudiantes de lengua árabe en el mundo hispanófono y a los estudiantes de lengua española en el mundo arabófono de las herramientas necesarias para poder avanzar en el conocimiento de ambas lenguas. Nos referimos a la publicación del Diccionario español-árabe (Corriente, 1970), con varias reediciones, reimpresiones y actualizaciones (Corriente, 1988a), hasta la última publicada en colaboración con Ahmed-Salem Ould-Mohamed Baba (Corriente \& Ould Mohamed-Baba, 2010), y del Diccionario árabe-español (Corriente, 1977a), también con varias reimpresiones, hasta la más actualizada, realizada con Ignacio Ferrando (Corriente \& Ferrando, 2005). Casi únicos instrumentos en nuestro país de los que disponían en esa época profesores, estudiantes, intérpretes, traductores y todo aquel que quisiera aproximarse al estudio de esta lengua, hasta que en 1996 apareciera el Diccionario de árabe culto moderno: árabe-español, de Julio Cortés, una obra que no sustituiría las anteriores sino que venía a com- 
plementarlas, y así lo oímos de labios de uno de los catedráticos de lengua árabe de este país cuando afirmó que «lo Cortés no quita lo Corriente».

A esta labor lexicográfica, hay que añadir además las sucesivas gramáticas de la lengua árabe, libros de textos y de ejercicios que han servido para la enseñanza y aprendizaje de esta lengua a tantos profesores y estudiantes, publicadas desde 1980 cuando apareció la primera Gramática Árabe (Corriente, 1980a), con múltiples ediciones y, posteriormente, la Introducción a la gramática y textos árabes (Corriente, 1986a), también con reimpresiones y reediciones diversas (Corriente, 1990), y el Vocabulario árabe graduado, en colaboración con Juan Pedro Monferrer Sala y Ahmed-Salem Ould Mohamed-Baba (Corriente, Monferrer Sala \& Ould Mohamed-Baba, 2013).

Centrándonos ahora en la producción investigadora de Federico Corriente, llegamos a otro aspecto muy productivo. En su bibliografía se cuenta casi medio centenar de libros y cerca de doscientos artículos, además de otras tantas conferencias en cursos y congresos que han permitido acceder a sus conocimientos a gente procedente de diversas naciones y en varias lenguas. Su obra científica, además de muy amplia, es fundamental en muchos campos del arabismo y su relación con el mundo romance, cambiando incluso, en algunos de ellos, el rumbo de la investigación desde la base. ${ }^{1}$

Dentro del amplio mundo del arabismo, Federico Corriente se ha atrevido con casi todas las especialidades, entre las que destacamos la historia, la literatura y, sobre todo, la dialectología, especialidad en la que su obra es conocida a nivel internacional y ha creado escuela.

Así pues, considerado pionero de estos estudios en España, es el fundador de un grupo de investigación que trabaja sobre los dialectos árabes magrebíes u occidentales y que le considera su maestro indiscutible. Su actividad se ha organizado en torno a siete proyectos de investigación trienales y consecutivos, entre 1990 y 2011, financiados por los distintos ministerios encargados de gestionar los planes nacionales de I+D+i y del que era el investigador principal. ${ }^{2}$ Los resultados de dichos proyectos se han dado a conocer como publi-

1 Con la intención de no convertir este artículo en una fría lista de publicaciones, citaremos solo los resultados en forma de libro y unos pocos artículos especialmente relevantes en la investigación del ámbito correspondiente. El número de artículos de revista y capítulos de libro sobre los distintos campos de estudio a los que se ha dedicado Federico Corriente es demasiado largo para incluir todos aquí. Un CV más completo puede verse en <http://www.unizar.es/estudiosarabes/miembros.html>.

2 Los cuatro últimos proyectos, desde 1999, fueron coordinados con la Universidad de Cádiz. 
caciones individuales, pero en muchas ocasiones también como publicaciones conjuntas con algunos de sus discípulos y/o colegas, una actividad que ha sido la raíz de su relación de estrecha colaboración con la mayoría de ellos y que han creado esa atmosfera de 'escuela' de dialectología árabe magrebí a la que nos referíamos más arriba. Si algo se puede negar de Federico Corriente es el haber sido un investigador aislado en su rincón zaragozano, escribiendo sus obras como autor único y sin contar con un equipo, algo que se puede comprobar en las numerosas obras en coautoría citadas en este artículo.

El árabe andalusí ha sido su tema de investigación predilecto, reconocido por él mismo, que incluso produjo un cambio en su vida. Su empeño en dar a conocer las fuentes que nos han transmitido datos sobre el andalusí se ha plasmado en la reedición continua de varias de ellas (ver infra las dedicadas a Ibn Quzmān), en la formación de doctorandos encargados de editar algunas otras en sus tesis doctorales, además de en la publicación de diccionarios y sucesivas gramáticas de esta lengua donde intenta sistematizar continuamente la información actualizada arrojada por los avances en los estudios realizados.

Son muchos sus logros con los que hemos llegado a conocer mejor la variedad vernácula de la lengua árabe hablada por la población de Alandalús: desde el cambio de nombre, sustituyendo el antiguo 'hispano-árabe' que tantas connotaciones tenía, por uno más apropiado 'árabe andalusí', hasta la primera gramática completa de esta lengua tan poco conocida hasta ese momento, como necesaria para entender algunas de las fuentes de la época escritas en árabe medio. Hablamos del A Grammatical Sketch of the Spanish-Arabic Dialect Bundle (Corriente, 1977b), cuya publicación supuso un hito en los estudios de dicha variedad árabe. Posteriormente otras obras han sido dedicadas a actualizar la información sobre este dialecto, como Árabe andalusí y lenguas romances (Corriente, 1992), A Descriptive and Comparative Grammar of Andalusi Arabic (Corriente, 2012) y, su última obra al respecto, en colaboración con Christophe Pereira y Ángeles Vicente, Aperçu grammatical du faisceau dialectal arabe-andalou. Perspectives synchroniques, diachroniques et panchroniques (Corriente, Pereira \& Vicente, 2015).

3 También ha acuñado el término romandalusí, con menor éxito, con el que nos referimos a la variedad romance hablada por la población andalusí. Y ha establecido que el nombre más apropiado de la entidad política arabo-musulmana que existió en gran parte de la Península Ibérica durante varios siglos es Alandalús, tal y como lo pronunciaban sus habitantes. 
Al conocimiento de la gramática de la lengua, por supuesto hay que añadir toda una labor lexicográfica que empezó con obras que recogían el vocabulario de las diversas fuentes de las que disponemos para conocer el árabe andalusí, como la de Pedro de Alcalá (Corriente, 1988b), el Vocabulista in Arabico (Corriente, 1989), el Glosario de Leiden (Corriente, 1991a) y el Dīwān de Ibn Quzmān (Corriente 1993). Tarea que tuvo como colofón la obra de recopilación A Dictionary of Andalusi Arabic (Corriente, 1997a).

También se ha preocupado Federico Corriente de la relación del andalusí con las lenguas peninsulares, y es por ello que sus estudios de los arabismos son numerosos; destacamos aquí su Diccionario de arabismos y voces afines en iberorromance (Corriente, 1999), corregido y aumentado en una edición posterior en 2003. Hasta llegar a la obra que recoge toda esta actividad lexicográfica, Dictionary of Arabic and Allied Loanwords Spanish, Portuguese, Catalan, Galician and Kindred Dialects (Corriente, 2008a).

El interés del Profesor Corriente por el léxico árabe, clásico y andalusí, y su relación con el romance, le ha llevado a fijar su atención en fuentes muy diversas, entre ellas los refranes, como la compilación que hizo con Hussein Bouzineb de los refranes de Alonso del Castillo (Corriente \& Bouzineb, 1994), y los glosarios botánicos medievales. En relación con estos últimos, su investigación, en colaboración con Joaquín Bustamante y Mohand Tilmatine, sobre el de Abulxayr ha dado como resultado tres volúmenes (Abulxayr, 20042010), uno con la edición del texto árabe en 2004, el segundo, publicado en 2007, contiene la traducción castellana y notas y, finalmente, los índices se publicaron en 2010.

Su investigación sobre obras fitonímicas ha continuado con otro texto del mismo género, el botánico de Alidrīsī, cuya edición y traducción, en colaboración con Ibrahim Benmrad, Joaquín Bustamante y Ana María Cabo, están ya en prensa.

Gracias a su meticuloso trabajo y a su continua dedicación para actualizar la información, hoy día podemos decir que el árabe andalusí es el dialecto árabe medieval mejor conocido. Así, sabemos que es el producto de la interacción entre los diversos dialectos árabes traídos por los invasores junto con el adstrato bereber de las tropas norteafricanas y el sustrato romance de la población local. El resultado de todo ello fue una lengua vernácula que llegó a ser la lengua dominante en territorio andalusí durante varios siglos y que tenía características únicas en el mundo arabófono; sirva de ejemplo, un ritmo 
prosódico cualitativo que distingue sílabas átonas y tónicas, en lugar del ritmo cuantitativo del árabe antiguo (Corriente, 1976a). Esta lengua tuvo el privilegio de convertirse en lengua literaria y, por ello, otro de los campos de estudio predilectos del profesor Corriente es la poesía estrófica, como veremos más adelante.

Pero en el campo de la lingüística no todo su esfuerzo lo acaparó el árabe andalusí, nunca ha dejado de ser ese semitista de formación que le gusta situar y comparar la lengua estudiada con su entorno inmediato, aquí destacamos su tesis doctoral que con el título Problemática de la pluralidad en semítico: el plural fracto (Corriente, 1971a) consiguió el premio extraordinario de doctorado. A esta obra hay que añadir algunos artículos que marcaron su trayectoria en este campo (Corriente, 1971b, 1973, 1975 y 1976b), sus tres traducciones del etiópico (Corriente, 1983, 1984 y 2009) y, especialmente, la Introducción a la gramática comparada del semítico meridional (Corriente, 1996). Además, en el campo de la dialectología árabe, fue el cofundador de la revista Estudios de dialectología norteafricana y andalusí, junto a Jordi Aguadé, y coeditor de los trece volúmenes publicados entre 1996 y 2009, a lo que se suma la edición en colaboración con Ángeles Vicente de la obra Manual de dialectología neoárabe (Corriente \& Vicente, 2008). También es el codirector de la colección Estudios de dialectología árabe, publicada en la actualidad por Prensas de la Universidad de Zaragoza y con once volúmenes aparecidos entre 2008 y 2016.

La actividad investigadora de Federico Corriente va a permitir un avance significativo del conocimiento no solo del árabe andalusí y de su relación con otras lenguas, sobre todo las habladas en la Península Ibérica, sino también en otros campos como la literatura, el folclore o la historia. Así ha sido, por ejemplo, en el campo de la lírica romance y la poesía estrófica árabe, al que ha contribuido con varios trabajos. Es especialmente destacable su dedicación a la compleja obra de Ibn Quzmān, a la que se ha acercado en diversas ocasiones, siempre con el mayor rigor y su gran capacidad lingüística que le han procurado el éxito: desde la primera edición completa (Corriente, 1980b); la segunda, revisada tras nuevas lecturas, publicada en Egipto (Corriente, 1995) y premiada en 1996 por el Ministerio de Cultura de la República Árabe Egipcia a la mejor edición de textos árabes, y luego reeditada en Rabat en 2013, y tres ediciones de la traducción, la primera en 1984 (Ibn Quzmān, 1984), luego corregida en una segunda edición (Ibn Quzmān, 1989) y corregida y completada en la tercera (Ibn Quzmān, 1996). 
La métrica de la poesía estrófica andalusí quedó bien establecida a partir de su investigación, en la que destacamos sendos artículos (Corriente, 1982 y 1986b). Otras poesías de autores andalusíes han sido objeto de su estudio, como las de Aššsuštarī (Corriente, 1988c) y de Ibn AlYarabī (Corriente \& Emery, 2004). A través del perfecto conocimiento de esas y otras fuentes, ha podido redactar una obra sobresaliente en la materia, Poesía dialectal árabe y romance en Alandalús (Corriente, 1997b), donde expone sus teorías y su extenso saber sobre ese tema controvertido tras meticulosos análisis de diversos autores andalusíes. Prueba de lo delicada que llegó a ser la cuestión en entornos romanistas e incluso entre algunos arabistas, es la publicación de Romania arabica. Tres cuestiones básicas: arabismos, «mozárabe»y «jarchas» (Corriente, 2008b).

De la misma manera que en el campo de la lingüística, en la literatura tiene un tema de trabajo predilecto, la poesía estrófica como hemos señalado, y otros a los que se dedica esporádicamente. Nos referimos a la literatura árabe moderna, tema con el que comenzó sus investigaciones, y a la literatura árabe preislámica.

Su trabajo sobre el teatro de Tawfīq Alḥakīm mereció el premio extraordinario de licenciatura de la Universidad Complutense de Madrid en 1963 y ese mismo año publicó la traducción al español del drama La gente de la caverna que había sido la base de esa Memoria (Alḥakīm, 1963). Poco tiempo después tradujo la novela El despertar de un pueblo del mismo autor (Alḥakīm, 1967). Su interés por la literatura árabe se ha mantenido y, así, intercalada con otros temas de estudio, ha seguido presente en sus publicaciones, como la traducción del original árabe de El profeta de Jubran Khalil Jubran en colaboración con Maḥmūd Șubḥ (Khalil, 1983). Pero no solo la literatura moderna ha sido objeto de su dedicación, también la antigua. En 1974 realizó la primera traducción al español de la antología tradicional de poesía árabe preislámica. Dicha traducción está hecha según los criterios, que él mismo expresa en la introducción, de claridad, fidelidad y análisis y se completa con una excelente introducción histórica y literaria (Corriente, 1974). La importancia de esa obra literaria y las novedades producidas en la investigación recomendaron su reedición, labor que emprendió años más tarde en colaboración con Juan Pedro Monferrer Sala. El resultado fue una nueva publicación actualizada y completada que revisa la traducción de los siete poemas editados anteriormente e incorpora tres nuevos, además de incluir adiciones en los comentarios literario e histórico y en el aparato crítico, lo que aporta más información, así como la actualización bibliográfica (Corriente \& Monferrer Sala, 2005). 
Su interés por los textos andalusíes le ha llevado también a la edición crítica anotada y a la traducción de crónicas históricas y obras jurídico-administrativas andalusíes. Esas fuentes, tras pasar por su competencia lingüística y su laboriosa dedicación para establecer unas lecturas correctas, resultan textos de calidad, perfectamente establecidos y totalmente fiables para los investigadores y estudiosos de diversos campos, como la historia medieval, la jurisprudencia y la literatura árabe de la Península Ibérica. Así, es de destacar su contribución a la historiografía andalusí con la edición, en colaboración con Pedro Chalmeta y Mạmmūd Șubḥ, del quinto volumen de Almuqtabis de Ibn Ḥayyān (Ibn Ḥayyān, 1979), la traducción del mismo junto a María Jesús Viguera (Ibn Hayyān, 1981) y la traducción de la primera parte del volumen segundo en colaboración con Mạ̣mūd ؟Alī Makkī (Ibn Hayyān, 2001).

Fruto de su profundo saber y un trabajo riguroso son también las ediciones, en colaboración con Pedro Chalmeta, de obras jurídico-administrativas andalusíes, como el formulario notarial de Ibn AlYatțār (Ibn AlYațtāar, 1983) y el tratado de hisba de Assaqațī (Assaqațī, 2014).

Así mismo, su edición y estudio de un texto aljamiado (Corriente, 1991b) ha contribuido a aumentar nuestro conocimiento, en este caso, de los últimos grupos de cultura arabo-islámica en la Península Ibérica.

Este artículo es un punto y seguido porque Federico Corriente sigue con muchas ideas aún en el tintero. Ahora como colaborador extraordinario del mismo departamento en el que lleva 34 años seguirá dando sus consejos, escribiendo sus publicaciones, participando en congresos e impartiendo conferencias, y, de vez en cuando, deleitándonos con uno de esos ácidos prólogos donde no deja títere con cabeza.

\section{Honores:}

- Premio extraordinario de Licenciatura, Universidad Complutense de Madrid.

- Premio extraordinario de Doctorado, Universidad Complutense de Madrid.

- Miembro correspondiente de la Academia de la Lengua Árabe de El Cairo, desde 1992.

- Premio del Ministerio de Cultura de la República Árabe de Egipto a la mejor edición de textos árabes (1995), por la del D̄̄wān de Ibn Quzmān. 
- Medalla de oro del Instituto Egipcio de Estudios Islámicos, concedida con ocasión del quincuagésimo aniversario de su fundación, en Madrid, $11 / 11 / 2000$.

- Homenaje de colegas y discípulos: Sacrum Arabo-Semiticum. Estudios en homenaje al prof. Federico Corriente en su 65 aniversario, editado por Jordi Aguadé, Ángeles Vicente y Leila Abu-Shams, Zaragoza, Instituto de Estudios Islámicos y del Oriente Próximo, 2005.

- Concesión del escudo de la Universidad de El Cairo, 21/3/2007.

- Certificado de aprecio del Departamento de Cultura e Información del Emirato de Ajman (Emiratos Árabes Unidos), el 13/3/2008.

- Miembro del Instituto de Estudios Canarios.

- Doctor honoris causa por la Universidad de La Laguna, 10/2/2015.

\section{Bibliografía:}

ABULXAYR AL?IŠBĪLĪ (2004, 2007 y 2010), Kitābu Gumdati țab̄̄b fī ma Grifati nnabāt likulli labīb (Libro base del médico para el conocimiento de la botánica por todo experto), edición, notas, traducción castellana, correcciones e índices de J. Bustamante, F. Corriente y M. Tilmatine, 3 vols., Madrid, Consejo Superior de Investigaciones Científicas.

ALHAKĪM, T. (1963), La gente de la caverna y tres piezas en un acto, traducción y nota de F. Corriente, Madrid, Instituto Hispano-Árabe de Cultura.

ALHAKĪM, T. (1967), El despertar de un pueblo, traducción de F. Corriente, Madrid, Instituto Hispano-Árabe de Cultura.

ASSAQATTI ALMĀLAQĪ (2014), El buen gobierno del zoco, edición de P. Chalmeta y F. Corriente, Almería, Fundación Ibn Tufayl de Estudios Árabes.

CORRIENTE, F. (1970), Diccionario español-árabe, Madrid, Instituto Hispano-Árabe de Cultura. Actualizado en el Nuevo diccionario español-árabe, Madrid, 1988. Reeditado en El Cairo, 1996 y reimpreso en Barcelona, 1997 y 2000.

- (1971a), Problemática de la pluralidad en semítico, Madrid, Consejo Superior de Investigaciones Científicas.

- (1971b), «On the functional yield of some synthetic devices in Arabic and Semitic morphology», Jewish Quarterly Review, 62, 20-50.

- (1973), «Again on the functional yield of some synthetic devices in Arabic and Semitic morphology», Jewish Quarterly Review, 64, 154-163.

- (1974), Las mu Gallaqāt: antología y panorama de la Arabia preislámica, Madrid, Instituto Hispano-Árabe de Cultura.

- (1975), «Marginalia on Arabic diglossia and evidence thereof in the Kitab alAghani», Journal of Semitic Studies, 20, 38-61. 
CORRIENTE, F. (1976a), «Acento y cantidad en la fonología del hispano-árabe», Al-Andalus, 41, 1-13.

- (1976b), «From Old Arabic to Classical Arabic through the pre-Islamic koine: some notes on the native grammarians' sources, attitudes and goals», Journal of Semitic Studies, 21, 62-98.

- (1977a), Diccionario árabe español, Madrid, Instituto Hispano-Árabe de Cultura. Reimpreso en 1986, y en Barcelona, Herder, 1991.

- (1977b) A Grammatical Sketch of the Spanish-Arabic Dialect Bundle, Madrid, Instituto Hispano-Árabe de Cultura.

- (1980a), Gramática árabe, Madrid, Instituto Hispano-Árabe de Cultura. Reimpreso en Barcelona, Herder, 1988, 1992 y ediciones sucesivas.

- (1980b), Gramática, métrica y texto del Cancionero hispanoárabe de Aban Quzmán, Madrid, Instituto Hispano-Árabe de Cultura.

- (1982), «The metres of the muwashshah, an Andalusian adaptation of Arud», Journal of Arabic Literature, 13, 76-82.

- (trad.) (1983), Libro de Jubileos, en Apócrifos del Antiguo Testamento II, Madrid, Cristiandad.

- (trad.) (1984), Libro de Henoc, en Apócrifos del Antiguo Testamento IV, Madrid, Cristiandad.

- (1986a), Introducción a la gramática y textos árabes, Madrid, Coloquio. Reeditado como Gramática y textos árabes elementales, Madrid, Hiperión, 1990.

- (1986b), «Again on the metrical system of muwashshah and zajal», Journal of Arabic Literature, 17, 34-49.

- (1988a), Nuevo diccionario español-árabe, Madrid, Instituto Hispano-Árabe de Cultura. Reimpreso en Barcelona, Herder, 1997 y 2000.

- (1988b), El léxico árabe andalusí según P. de Alcalá, Madrid, Universidad Complutense de Madrid.

- (1988c), Poesía estrófica (cejeles y/o muwaššaḥāt) atribuida al místico granadino Aššuštarī, Madrid, Consejo Superior de Investigaciones Científicas.

- (1989), El léxico árabe andalusí según el Vocabulista in Arabico, Madrid, Universidad Complutense de Madrid.

- (1990), Gramática y textos árabes elementales, Madrid, Hiperión.

- (1991a), Léxico estándar y andalusí del Glosario de Leiden, Madrid, Universidad Complutense de Madrid.

- (1991b), Relatos píos y profanos del ms. aljamiado de Urrea de Jalón, Zaragoza, Institución Fernando el Católico.

- (1992), Árabe andalusí y lenguas romances, Madrid, MAPFRE. Reeditado en CD-ROM en 1997.

- (1993), Léxico estándar y andalusí del Dīwān de Ibn Quzmān, Zaragoza, Área de Estudios Árabes e Islámicos.

- (1995), Dīwān Ibn Quzmān Alqurțubī (Ișābatu lPagrād fị dikri l Pa Yrāde), El Cairo, Consejo Superior de Cultura. Reeditado en Rabat, Dār Abī Raqrāq, 2013. 
CORRIENTE, F. (1996), Introducción a la gramática comparada del semítico meridional, Madrid, Consejo Superior de Investigaciones Científicas.

- (1997a), A Dictionary of Andalusi Arabic, Leiden, Brill.

- (1997b), Poesía dialectal árabe y romance en Alandalús, Madrid, Gredos.

- (1999) Diccionario de arabismos y voces afines en iberorromance, Madrid, Gredos. $2^{\text {a }}$ ed. corregida y aumentada en 2003.

- (2008a), A Dictionary of Arabic and Allied Loanwords Spanish, Portuguese, Catalan, Galician and Kindred Dialects, Leiden, Brill.

- (2008b), Romania arabica. Tres cuestiones básicas: arabismos, «mozárabe»y «jarchas», Madrid, Trotta.

- (trad.) (2009), Ascensión de Isaías, en Apócrifos del Antiguo Testamento VI, Madrid, Cristiandad.

- (2012), A Descriptive and Comparative Grammar of Andalusi Arabic, Leiden-Boston, Brill.

CORRIENTE, F. y BOUZINEB, H. (1994), Recopilación de refranes andalusíes de Alonso del Castillo, Zaragoza, Área de Estudios Árabes e Islámicos.

- y EMERY, E. (2004), Twenty-Seven Muwashshahaat and One Zajal by Ibn alSArabi of Murcia (1165-1240), London-Zaragoza.

- y FERRANDO, I. (2005), Diccionario avanzado árabe, Tomo I árabe-español, Barcelona, Herder.

- y MONFERRER SALA, J.P. (2005), Las diez Mu Gallaqāt. Poesía y panorama de Arabia en vísperas del Islam. (Traducción literal y completa de los diez poemas originales anotada y comentada en los aspectos literario e histórico), Madrid, Hiperión.

- MONFERRER SALA, J.P. y OULD MOHAMED-BABA, A.-S. (2013), Vocabulario árabe graduado, Barcelona, Herder.

- y OULD MOHAMED-BABA, A.-S. (2010), Diccionario avanzado árabe. Tomo II: español- árabe, Barcelona, Herder.

- PEREIRA, CH. y VICENTE, Á. (2015), Aperçu grammatical du faisceau dialectal arabe-andalou. Perspectives synchroniques, diachroniques et panchroniques, Berlín, De Gruyter.

- y VICENTE, Á. (eds.) (2008), Manual de dialectología neoárabe, Zaragoza, Instituto de Estudios Islámicos y Próximo Oriente.

CORTÉS, J. (1996), Diccionario de árabe culto moderno: árabe-español, Madrid, Gredos.

IBN AL ATTṬĀR (1983), Formulario notarial hispano-árabe (siglo X), edición de P. Chalmeta y F. Corriente, Madrid, Instituto Hispano-Árabe de Cultura \& Academia Matritense del Notariado.

IBN HaYYYĀN (1979), Al-Muqtabas V, edición de P. Chalmeta, F. Corriente y M. Șubḥ, Madrid, Instituto Hispano-Árabe de Cultura. 
IBN HAYYĀN (1981), Crónica del califa Abderrahman III Annasir entre los años 912 y 942 (al-Muqtabis V), traducción, notas e índices de M.J. Viguera y F. Corriente, Zaragoza, Anubar e Instituto Hispano-Árabe de Cultura.

- (2001), Crónica de los emires Alhakam I y SAbdarraḥmān II entre los años 796 y 847 (Almuqtabis II-1), traducción, notas e índices de M. A. Makkī y F. Corriente, Zaragoza, Instituto de Estudios Islámicos y del Oriente Próximo.

IBN QUZMĀN (1984), El Cancionero hispanoárabe, edición preparada por F. Corriente, Madrid, Editora Nacional.

- (1989), Cancionero andalusí, edición de F. Corriente, Madrid, Hiperión.

- (1996), Cancionero andalusí (edición íntegra de cejeles y fragmentos), traducción, introducción y notas de F. Corriente, Madrid, Hiperión.

KHALIL JUBRAN, J. (1983), El Profeta, traducción de M. Șubḥ y F. Corriente, Madrid, Sílex. 